\title{
Successful shockwave intravascular lithotripsy for a severely calcified and undilatable left anterior descending coronary artery lesion in a patient with recurrent myocardial infarction
}

Jacek Legutko', Łukasz Niewiara', Marek Tomala', Wojciech Zajdel', Monika Durak1,

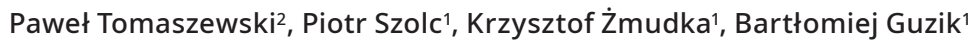

1 Department of Interventional Cardiology, Institute of Cardiology, Jagiellonian University Medical College, John Paul II Hospital, Kraków, Poland

2 Department of Cardiology, District Hospital, Starachowice, Poland

Correspondence to: Jacek Legutko, MD, PhD, Department of Interventional Cardiology, Institute of Cardiology, Jagiellonian University Medical College, John Paul II Hospital, Kraków, Poland,

ul. Prądnicka 80, 31-202 Kraków, phone: +48126143501,

email: jacek.legutko@uj.edu.pl Received: May 27, 2019.

Revision accepted: June 4, 2019 Published online: June 6, 2019. Kardiol Pol. 2019; 77 (7-8): 723-725 doi:10.33963/KP.14859 Copyright by the Author(s), 2019
Successful coronary stent implantation is challenging in the presence of severe calcifications. Adequate lesion preparation before stenting is crucial to avoid severe procedural and late complications. Lesion predilation with a noncompliant, scoring, or cutting balloon is a standard of care; however, it does not provide optimal stent expansion and apposition. Rotational and orbital
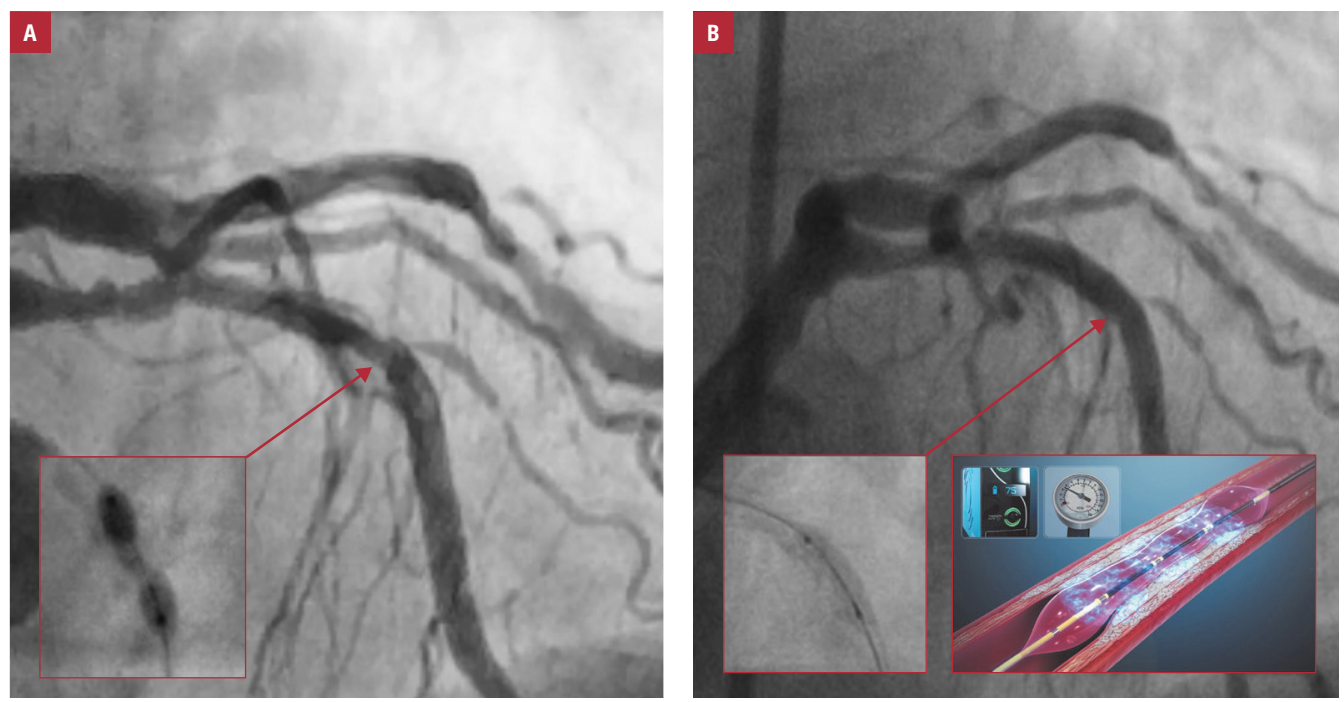

FIGURE 1 A - baseline left anterior descending coronary artery angiogram; partial dilation of the cutting balloon at high pressure (insert); the outcome of primary percutaneous coronary intervention, with undilated space between stents (arrow); B - outcome of intravascular lithotripsy (arrow); the Shockwave balloon fully opened at 6 atm (insert) atherectomy is indicated in selected cases, but it is associated with a higher risk of procedural complications. ${ }^{1}$

Coronary intravascular lithotripsy (IVL) is a new technique designed to facilitate percutaneous coronary intervention (PCI) in calcified lesions, with encouraging results from clinical trials. ${ }^{2}$ The Shockwave IVL catheter (Shockwave Medical, Fremont, California, United States) 
FIGURE 1 C - intravascular ultrasound (IVUS) and optical coherence tomography (OCT) cross-sections after intravascular lithotripsy from the distal to the proximal part of the LAD; crackles in plaque (white arrow); D IVUS and OCT cross-sections with symmetric, full opening of the drug-eluting stent in previously undilatable lesion
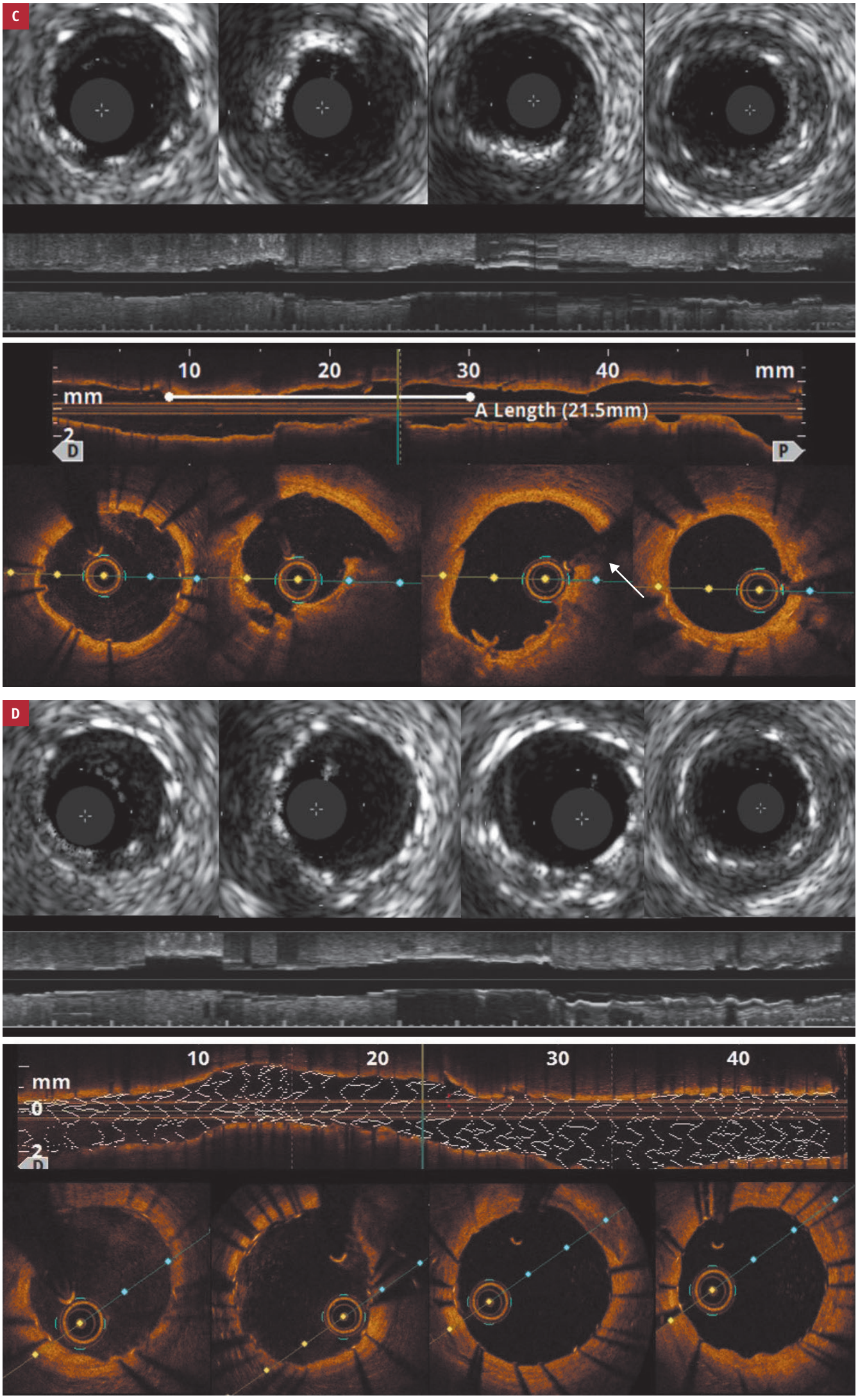

contains multiple lithotripsy emitters on a balloon. Sonic waves, produced circumferentially, selectively fracture calcium, altering vessel compliance, maintaining the fibroelastic architecture, and allowing full balloon opening at low pressures (4-6 atm).
We present a case of a 79-year-old woman who underwent the first successful treatment with a Shockwave C2 IVL catheter at our institution.

The patient had a history of diabetes, arterial hypertension, moderate chronic kidney disease, and PCI in the left anterior descending coronary 
artery (LAD) in 2007. She was admitted to a regional center with anterior-wall ST-segment elevation myocardial infarction as a complication of knee alloplasty. An emergency angiography revealed severely calcified critical narrowing of the LAD (FIGURE 1A). Several inflations with a noncompliant balloon (2.5-2.75 $\mathrm{mm}$ ) were unsuccessful (FIGURE 1A) and resulted in type B/C dissection distal to the stenosis, which was treated with 2 drug-eluting stents, leaving an undilated lesion between the stents (FIGURE 1A).

A few days later, the patient experienced recurrent angina at rest as well as ventricular tachyarrhythmia and was referred to our center for repeat high-risk PCI. Rotational atherectomy was considered but was not performed due to a higher risk of complications associated with a history of recurrent myocardial infarction and the presence of a newly implanted stent at the distal edge of the culprit stenosis. ${ }^{1,3}$ To facilitate adequate preparation of the undilatable lesion, we decided to use IVL (FIGURE 1B). A transfemoral approach using an 7F extra-back-up guiding catheter was chosen. Neither baseline intravascular ultrasound (IVUS) nor optical coherence tomography (OCT) imaging was possible because both catheters did not cross the lesion. Predilation with a noncompliant balloon ( $2.5 \mathrm{~mm}$; max. 16 atm) was performed, which allowed a successful delivery of the Shockwave C2 catheter $(3.0 \times 12 \mathrm{~mm})$ to the culprit lesion. Sixty applications (at $4 \mathrm{~atm}$ ) in the middle and proximal parts of the LAD were done (FIGURE 1B), achieving full dilation of the IVL balloon at $6 \mathrm{~atm}$. The IVUS and OCT images obtained after IVL revealed the presence of calcium cracks at the culprit lesion (FIGURE 1 C). Then, an ultra-thin $(60 \mu \mathrm{m})$ drug-eluting stent $(3.0 \times 30 \mathrm{~mm})$ was successfully implanted, with proper overlap with previously implanted stents. Control angiography, IVUS, and OCT confirmed optimal PCI outcome with perfect stent expansion and apposition (FIGURE 1D). No complications occurred during hospitalization and the patient was discharged home 48 hours after the procedure, free of angina and ventricular arrhythmia.

\section{ARTICLE INFORMATION}

CONFLICT OF INTEREST None declared.

OPEN ACCESS This is an Open Access article distributed under the terms of the Creative Commons Attribution-NonCommercial-NoDerivatives 4.0 International License (CC BY-NC-ND 4.0), allowing third parties to download articles and share them with others, provided the original work is properly cited, not changed in any way, distributed under the same license, and used for noncommercial purposes only. For commercial use, please contact the journal office at kardiologiapolska@ptkardio.pl.

HoW TO CITE Legutko J, Niewiara $Ł$, Tomala M, et al. Successful shockwave intravascular lithotripsy for a severely calcified and undilatable left anterior descending coronary artery lesion in a patient with recurrent myocardial infarction. Kardiol Pol. 2019; 77: 723-725. doi:10.33963/KP.14859
2 Brinton TJ, Ali ZA, Hill JM, et al. Feasibility of shockwave coronary intravascular lithotripsy for the treatment of calcified coronary stenoses. Circulation. 2019; 139: 834-836.

3 Neumann FJ, Sousa-Uva M, Ahlsson A, et al. 2018 ESC/EACTS Guidelines on myocardial revascularization. Eur Heart J. 2018; 40: 87-165.

\section{REFERENCES}

1 Dobrzycki S, Reczuch K, Legutko J, et al. Rotational atherectomy in everyday clinical practice. Association of Cardiovascular Interventions of the Polish Society of Cardiology: expert opinion. Kardiol Pol. 2018; 76: 1576-1584. 